\title{
RESEARCH ON MODULE-BASED VARIANT DESIGN FOR MASS CUSTOMIZATION
}

\author{
Junjian Ding, Shili Tan, Haihong Zhang, Xiaofeng Song \\ School of Mechanical\&Electronic Engineering and Automation, Shanghai University, China; \\ Email:ddajian@sohu.com
}

\begin{abstract}
The mass customization can make customized products with the mass products efficiency, which will become mainstream manufacturing mode in the 21 century. The design for mass customization is the most important factor in the mass customization, on the base of extracting the excellences of the modulization design and the variant design, the article brings forward an idea of module-based variant design. Combining with the technologies of module coding, database, case-based design and $\mathrm{CAD}$, The idea has been used in the customized design of the equipment of pushing and measuring automobile chair track, some equipments have been designed and manufactured successfully.
\end{abstract}

Key words: Mass Customization; Modulization Design; Variant Design; Module-Based Variant Design

\section{INTRODUCTION}

The mass customization can make customized products with the mass products efficiency. Like the status of the mass products in the earlier of 20 century, the mass customization which is the coming reformation will take great changes in manufacturing. In order to realize the strategic target in manufacturing, some developed countries have applied mass customization to small amount or single product customization, and the ideas and methods of

This project is supported by the scientific development foundation of Shanghai Automobile Industry under the grant No. 0212 .

Please use the following format when citing this chapter:

Ding, Junjian, Tan, Shili, Zhang, Haihong, Song, Xiaofeng, 2006, in International

Federation for Information Processing (IFIP), Volume 207, Knowledge Enterprise:

Intelligent Strategies In Product Design, Manufacturing, and Management, eds. K. Wang,

Kovacs G., Wozny M., Fang M., (Boston: Springer), pp. 1022-1029. 
mass customization have been looked as the important measure, at the same time, the design for mass customization is the most important factor. ${ }^{8,9}$

Each of modulization design and variant design is one of the key methods of the mass customization. However when the transverse and longitudinal variants are occurred in the mass customized products, the modulization or variant design can not accomplish the design singly. The transverse variant is that the function, form and structure of a product family are changeless, while the size of the component is changeable. The longitudinal variant is that the function of a product family is changeless, while the form and structure are changeable. So the article brings forward a method-----module-based variant design, the method has been used in the designs and equipments to make the automobile chair tracks.

\section{MODULIZATION DESIGN}

Modulization design is a design method facing the whole product family. On the base of forecasting products market and analyzing products function, the product family is been divided into a series of general modules. According to the customers' demands, modulization design can select and reconfigure different modules, and get a new product, which function, performance and specification are different with the old ones.

Modulization design is one of the key factors of the mass customization, it can make good use of the design resource effectively, reduce the management and assembly cost, simplify the design process and renew the product, at the same time it is good at managing and maintain the product during its life cycle. However using this method, the design system can become complicated, the product structure can not be harmony, the assembly fit can not be very well.

In generally, the model of the product family includes three parts $\left.{ }^{3}, 1\right)$ function model, it expresses the function, elements of the function and performance owned by the product. 2) principle model, it expresses the method used in mapping function model to structure model, and the method includes some knowledge, such as design constraint, calculation relation and the control of design process. 3) structure model, it expresses the assembly level of the product family and the possible structures of all modules.

According to the components of the product family, it is easy to get the map from the function model to the structure model, and modules of the product family. 


\section{VARIANT DESIGN}

Variant design is another design method, the new product can be got by using it, which has the same principle, similar structure comparing with the old products, while partial structure and/or design parameter of the old products have been changed. At present, most of mechanical designs belong to variant design, few of them is innovation design ${ }^{2}$. In innovation design, some existed products or components can not been reused, but they can enlighten the designer. In an equipment designed by innovation design, the reused components accounts for about $40 \%$, the ratio of the components amended from the existed ones is about $40 \%$, there is about $20 \%$ is the new component. Variant design suits for longitudinal change of the mass customization product mainly ${ }^{1}$.

Case-based design (CBD) is one of the common methods of variant design ${ }^{4,5,7,8}$, it is an application of CBR (Case-based reasoning) technology in the field of CAD. The CBR is one of Artificial Intelligence technologies, so the CBD can well present the characters of variant design, such as generalization, process and individuation. CBR includes questioning, exploring, extracting, evaluating, and storing ${ }^{6}$. According to customers demands, The CBD extracts the similar or same case from the existed database, then analyzes the case's structure and parameter, if they meets the design requests, they can look as the object of the design, or if they can partly meet, CBD will amend them until they are well.

\section{MODULE-BASED VARIANT DESIGN}

In order to realize the transverse and longitudinal variant of the mass customization, combining modulization design with variant design gets the method of module-based variant deign, which has been applied in the some designs. Figure 1 shows the processes of the module-based variant design.

In fact, module-based variant design is the method applying the idea of modulization design into the variant design, it has the flexibility of variant design and overcomes the rigidity of modulization design. Using it can shorten the time of design and manufacture, reduce the cost and improve the quality, the products also have great advantages to response the market needs for many kinds and small batch products. 


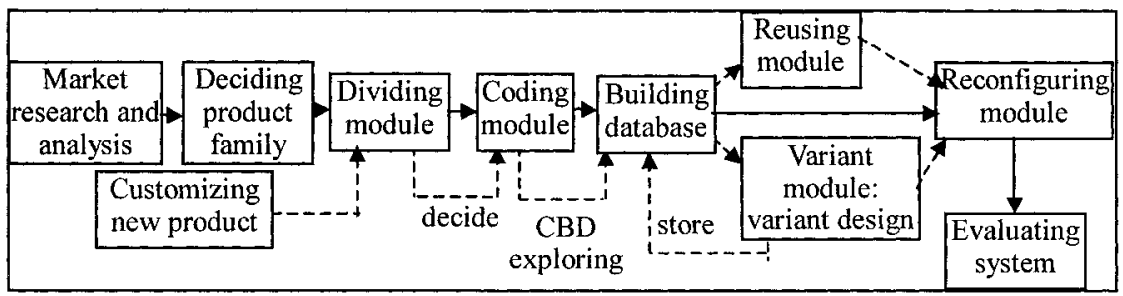

Figure 1. the processes of the module-base variant design

\section{CASE}

With the development of automobile industry, the people's needs take on individual trend, and the kinds of automobile chair become more and more (such as, different chairs can move in two, four, six, or eight direction, and their fixing modes are different), while they have the same character, the track is their basic safe component, so the product lines of the automobile chairs are similar. At present, the automobile chair manufacturing line can be looked as the kind of such products which are designed and made individually.

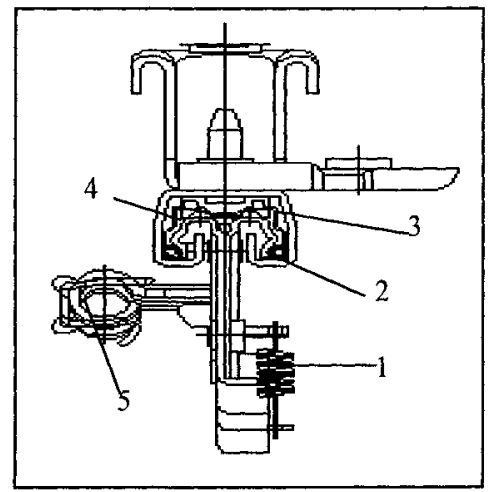

Figure 2. side-glance of the chair track

1. lock spring 2. upper slotware 3.bearing parts 4. lower slotware 5.lock structure 
The automobile chair track mainly includes: upper slotware, lower soltware and front and behind bearing parts(such as figure 2). The lower slotware is fixed on the automobile, the upper slotware can move along the lower. The bearing part has some steel balls and a bracket, which is been thrust into the track and between the upper and the lower slotware, when the steel balls rolled, the relative movement between the upper and the lower can be occurred. When the bearing part is thrust into the track, the upper, the lower and the bearing part

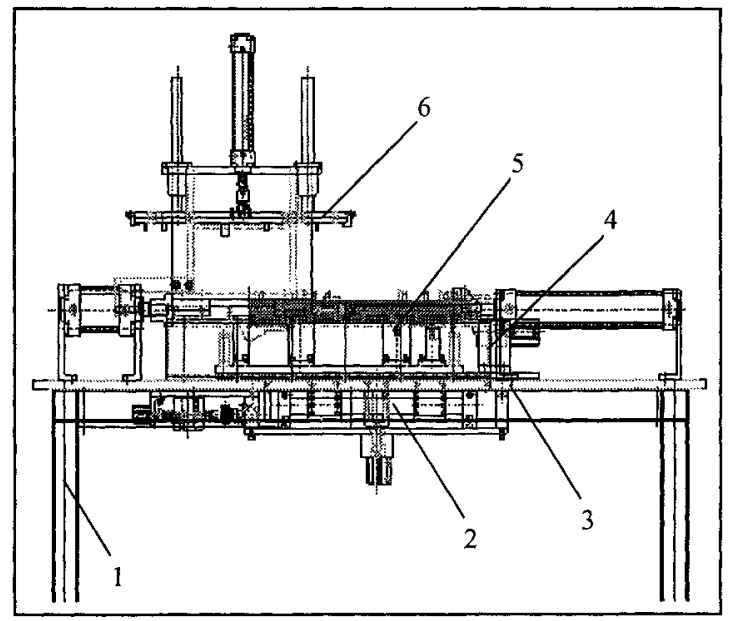

Figure 3. Hcar rover $\mathrm{p} 32 \mathrm{e}-$ the equipment of pushing and measuring track

1.support shelf 2. measure part 3.worktable 4.clamp part 5.orientation part 6.load/push part

integrate tightly, in order to measure the force of track's relative movement, at first, the track must been pushed and become flexible, then the force can be measured precisely.

The equipment of pushing and measuring track can attain the former task, and it is one of the key equipments in the automobile chair track manufacturing line. Figure 3 shows its structures.

After researching and analyzing the market of the equipments of pushing and measuring track, the equipments can be divided into some modules, figure 4 shows the map of function-structure modules of the equipments. The load module can simulate the real environment to load the vertical force on the track. The unlock module can disable the lock structure in the track, so the upper and lower slotware can move relatively. In figure 4 , the basic module and auxiliary 
module can form the prototype equipment, the special module and additional module can extend the function of the equipment.

Analyzing all the equipments, each module includes some different contents:

Orientation module: pin orientation, block orientation.

Unlock module: upper unlock module, lower unlock module.

Table 1. the sum table of different equipment of pushing and measuring track and different tracks

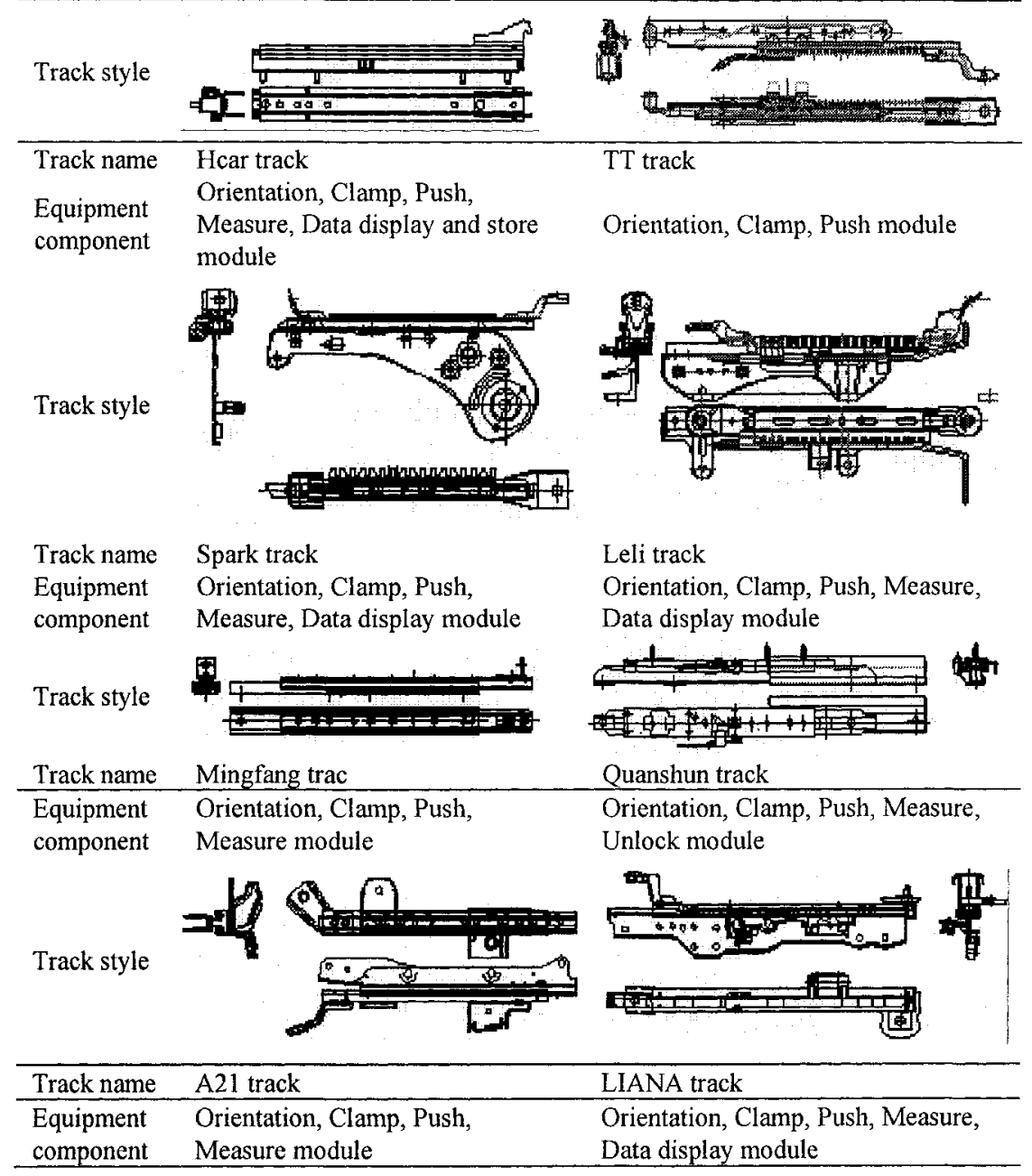


Clamp module: across clamp module, axis-direction clamp module.

Push module: driving push, pushing push, pulling push.

Load module: single load, pushing-loading load.

Measure, data display, and data store module are the common module in all the equipments.

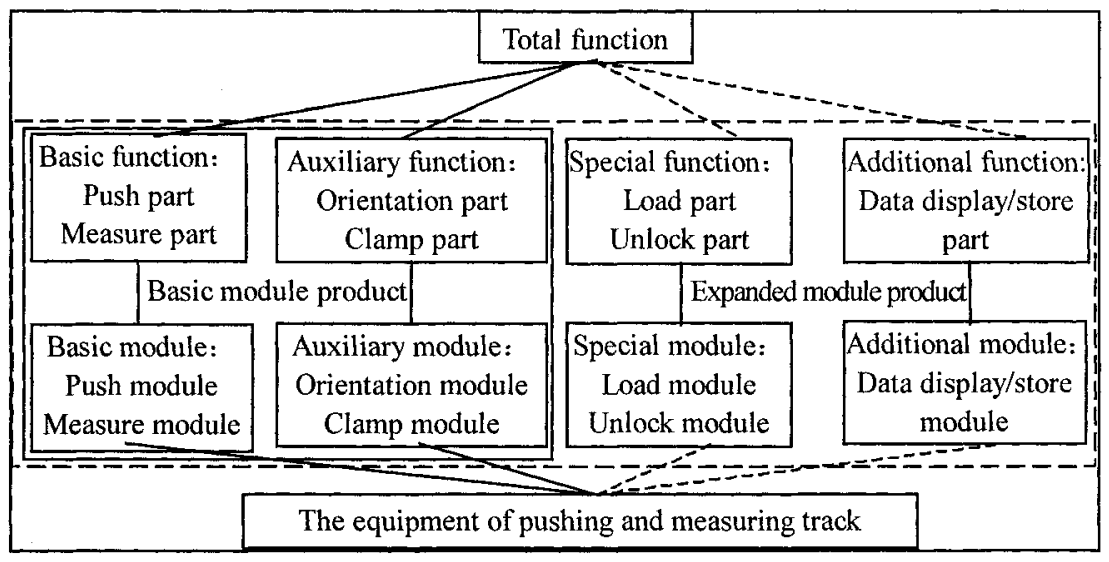

Figure 4. the map of function-structure modules of the equipment

Table 1 includes the most styles of the existing chair tracks. When designing the equipment of pushing and measuring track, the modules is been divided, the codes is been get, the database is been built. If there is a new customized demand, the designer will divide the customized equipment into different modules, code them and explore them in the database according to CBD rules. When the requested module is in the database, it will be used right away, if the requested module is not, the system will find a similar module, so the designer can do variant design on the base of the similar module, at last, the new module will be stored in the database.

\section{SUMMARY AND PROSPECT}

By using the module-base variant design, all the equipments in the table 1 have been designed and employed, a general database which can meet the current customized demands for the equipment of pushing and measuring track has been built, at the same time, it can been extended. The module-based variant 
design can be applied into other mass customization products which have the characters of many kinds and small batch.

Some evaluations are needed in the module-based variant design process, they can not only evaluate the design result, but also supply reasons to improve the product, and the evaluation is a key tool to get knowledge. So the evaluation system, which includes evaluation index, evaluation module, analysis method and so on, will become a future research emphasis.

\section{REFERENCES}

1. Dobrescu G, Reich Y, (2003), Progressive sharing of modules among product variants, Computer-Aided Design, vol. 3, pp.791-806

2. Zhong Tingxiu, (2004), Theory and method of rapid response product design, Hydraulics Pneumatics\&Seals, vol.4, pp.4-9

3. Zeng Fengfang, You Xiao, Yan Xiaoguang, (2004), Technology research on product family modeling under mass customization, Computer and Digital Engineering, vol.2, pp.48-50

4. Jiang Li, Sun Shouqian, (1997), An intelligent variant-design supporting system model, KonstruKtion, vol.3, pp.14-19

5. Luo Haiyu, (2001), Design strategy for rapid variant design of mechanical products, Mechanical Research\&Applicatin, vol.12, pp.69-71

6. Zhao Jiyun, Zhong Tingxiu, (1999), The key techniques and application of CBD system to the variant design, Mechanical Design and Research, vol.2, pp.36-40

7. Mechanical Design Handbook edition two( China Machine Press, Beijing, 2003.6)

8. Hwai-En Tseng, Chien-Chen Chang, (2005), Applying case-based reasoning for product configuration in mass customization environments, Expert Systems with Applications, vol.29, pp.913-925

9. Jari Partanen, Harri Haapasalo, (2004), Fast production for order fulfillment: Implementing mass customization in electronics industry, Production Economics, vol.90, pp.213-222 